NASA/TM-2003-212518

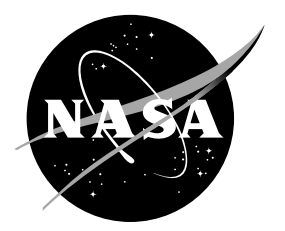

\title{
Microstructural and Defect Characterization in Ceramic Composites Using an Ultrasonic Guided Wave Scan System
}

D.J. Roth

Glenn Research Center, Cleveland, Ohio

L.M. Cosgriff and R.E. Martin

Cleveland State University, Cleveland, Ohio

M.J. Verrilli

Glenn Research Center, Cleveland, Ohio

R.T. Bhatt

U.S. Army Research Laboratory, Glenn Research Center, Cleveland, Ohio 
Since its founding, NASA has been dedicated to the advancement of aeronautics and space science. The NASA Scientific and Technical Information (STI) Program Office plays a key part in helping NASA maintain this important role.

The NASA STI Program Office is operated by Langley Research Center, the Lead Center for NASA's scientific and technical information. The NASA STI Program Office provides access to the NASA STI Database, the largest collection of aeronautical and space science STI in the world. The Program Office is also NASA's institutional mechanism for disseminating the results of its research and development activities. These results are published by NASA in the NASA STI Report Series, which includes the following report types:

- $\quad$ TECHNICAL PUBLICATION. Reports of completed research or a major significant phase of research that present the results of NASA programs and include extensive data or theoretical analysis. Includes compilations of significant scientific and technical data and information deemed to be of continuing reference value. NASA's counterpart of peerreviewed formal professional papers but has less stringent limitations on manuscript length and extent of graphic presentations.

- TECHNICAL MEMORANDUM. Scientific and technical findings that are preliminary or of specialized interest, e.g., quick release reports, working papers, and bibliographies that contain minimal annotation. Does not contain extensive analysis.

- CONTRACTOR REPORT. Scientific and technical findings by NASA-sponsored contractors and grantees.
- CONFERENCE PUBLICATION. Collected papers from scientific and technical conferences, symposia, seminars, or other meetings sponsored or cosponsored by NASA.

- SPECIAL PUBLICATION. Scientific, technical, or historical information from NASA programs, projects, and missions, often concerned with subjects having substantial public interest.

- TECHNICAL TRANSLATION. Englishlanguage translations of foreign scientific and technical material pertinent to NASA's mission.

Specialized services that complement the STI Program Office's diverse offerings include creating custom thesauri, building customized databases, organizing and publishing research results ... even providing videos.

For more information about the NASA STI Program Office, see the following:

- Access the NASA STI Program Home Page at http://www.sti.nasa.gov

- E-mail your question via the Internet to help@sti.nasa.gov

- Fax your question to the NASA Access Help Desk at 301-621-0134

- Telephone the NASA Access Help Desk at 301-621-0390

- Write to:

NASA Access Help Desk

NASA Center for AeroSpace Information 7121 Standard Drive

Hanover, MD 21076 
NASA/TM-2003-212518

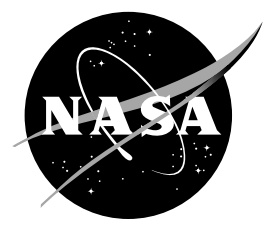

\section{Microstructural and Defect Characterization in Ceramic Composites Using an Ultrasonic Guided Wave Scan System}

D.J. Roth

Glenn Research Center, Cleveland, Ohio

L.M. Cosgriff and R.E. Martin

Cleveland State University, Cleveland, Ohio

M.J. Verrilli

Glenn Research Center, Cleveland, Ohio

R.T. Bhatt

U.S. Army Research Laboratory, Glenn Research Center, Cleveland, Ohio

Prepared for the

30th Annual Review of Quantitative Nondestructive Evaluation (QNDE) sponsored by the Quantitative Nondestructive Evaluation (QNDE) Programs Green Bay, Wisconsin, July 27-August 1, 2003

National Aeronautics and

Space Administration

Glenn Research Center 
Trade names or manufacturers' names are used in this report for identification only. This usage does not constitute an official endorsement, either expressed or implied, by the National Aeronautics and Space Administration.

Available from

NASA Center for Aerospace Information 7121 Standard Drive

Hanover, MD 21076
National Technical Information Service 5285 Port Royal Road Springfield, VA 22100

Available electronically at http:/ /gltrs.grc.nasa.gov 


\title{
MICROSTRUCTURAL AND DEFECT CHARACTERIZATION IN CERAMIC COMPOSITES USING AN ULTRASONIC GUIDED WAVE SCAN SYSTEM
}

\author{
D.J. Roth \\ National Aeronautics and Space Administration \\ Glenn Research Center \\ Cleveland, Ohio 44135 \\ L.M. Cosgriff* and R.E. Martin ${ }^{*}$ \\ Cleveland State University \\ Cleveland, Ohio 44115 \\ M.J. Verrilli \\ National Aeronautics and Space Administration \\ Glenn Research Center \\ Cleveland, Ohio 44135 \\ R.T. Bhatt \\ U.S. Army Research Laboratory \\ Glenn Research Center \\ Cleveland, Ohio 44135
}

\begin{abstract}
In this study, an ultrasonic guided wave scan system was used to characterize various microstructural and flaw conditions in two types of ceramic matrix composites, $\mathrm{SiC} / \mathrm{SiC}$ and $\mathrm{C} / \mathrm{SiC}$. Rather than attempting to isolate specific lamb wave modes to use for characterization (as is desired for many types of guided wave inspection problems), the guided wave scan system utilizes the total (multimode) ultrasonic response in its inspection analysis. Several time- and frequency-domain parameters are calculated from the ultrasonic guided wave signal at each scan location to form images. Microstructural and defect conditions examined include delamination, density variation, cracking, and pre/post-infiltration. Results are compared with thermographic imaging methods. Although the guided wave technique is commonly used so scanning can be eliminated, applying the technique in the scanning mode allows a more precise characterization of defect conditions.
\end{abstract}

\section{INTRODUCTION}

Ceramic matrix composites (CMCs) are being developed for advanced aerospace propulsion applications in order to save weight, to improve reuse capability, and to increase performance. However, mechanical and environmental loads applied to CMCs can cause degradation in the form of discrete flaws and distributed micro-damage that plays a significant role in reduction of desirable physical properties. Categories of microdamage include fiber/matrix debonding [interface failure], matrix microcracking, fiber fracture and buckling, oxidation, and second phase formation. A recent study of the durability of a ceramic matrix composite, $\mathrm{C} / \mathrm{SiC}$, discussed the requirement for improved nondestructive evaluation (NDE) methods for monitoring degradation in these materials. Distributed micro-damage in CMCs has proven difficult to characterize nondestructively due to the complex micro- and macro-structure of these materials. This article discusses the use of an ultrasonic guided wave scan system to characterize various microstructural and flaw conditions in $\mathrm{SiC} / \mathrm{SiC}$ and $\mathrm{C} / \mathrm{SiC}$ ceramic matrix composite samples.

Ultrasonic guided wave inspection is generally thought of as an attractive alternative to scanning because guided waves can be excited at one location of a structure by a single transducer or line of transducers with returning or received echoes indicating

*NASA Resident Research Associate at Glenn Research Center. 
the presence of defects [2-6]. This type of inspection has seen success detecting flaws and material degradation in many types of materials and components, and in some applications over significant distances. The guided wave signal in raw form is very complex (many dispersive and interfering modes present traveling at different velocities) with significant coherent noise that cannot be averaged out. As a result, guided wave methods seem to be most successful for flaw detection when tuning for a minimally- or non-dispersive mode of ultrasound, at a particular excitation frequency, in one direction, in order to control coherent noise [2,5]. The guided wave method discussed in this article takes a different approach by utilizing the total (multi-mode) ultrasonic response, doing so in a scanning configuration, and employing specialized signal processing routines to extract parameters of the time- and frequency-domain signals $[4,6,7]$. These parameters have proven to be sensitive to changes in microstructural conditions [4,6,7] and to the presence of defects [8], and appear promising at monitoring degradation in CMCs [9].

\section{ULTRASONIC MULTI-MODE GUIDED WAVE SCAN METHOD}

\section{$\underline{\text { Measurement }}$}

The multi-mode guided wave method is a single-sided technique with the basic measurement employing separated sending and receiving transducers at normal incidence to the sample similar to acousto-ultrasonic interrogation (figure 1) [4,6]. Ultrasonic guided waves through the material thickness are generated when the ultrasonic wavelength is on the order of the thickness of the material being interrogated. The key factor in multi-mode ultrasonic guided wave interrogation is that the relationship between the ultrasonic wavelength $(\lambda)$ and material thickness (h) results in a diffuse field of multiple plate wave modes [4].

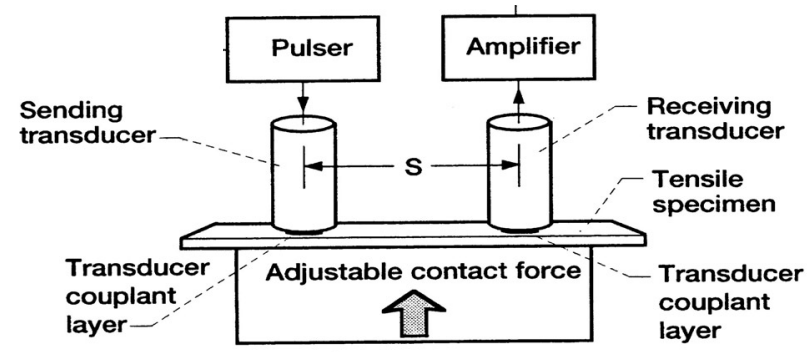

FIGURE 1. Schematic of multi-mode guided wave experimental setup. $\mathrm{S}=$ distance between sending and receiving transducers.

Although guided wave techniques are commonly used so scanning can be eliminated, applying the techniques in the scanning mode likely allows a more precise characterization (location, size, shape) of defect conditions. For example, although a simple guided wave method may determine whether a defect does or does not exist, a guided wave scanning technique may be able to image the same defect and allow more accurate identification of type and more accurate size estimation $[7,8]$. The scan setup is shown in figure 2 .

Depending on the situation, there may be several further advantages of using guided wave scanning over conventional ultrasonic methods. These include: 


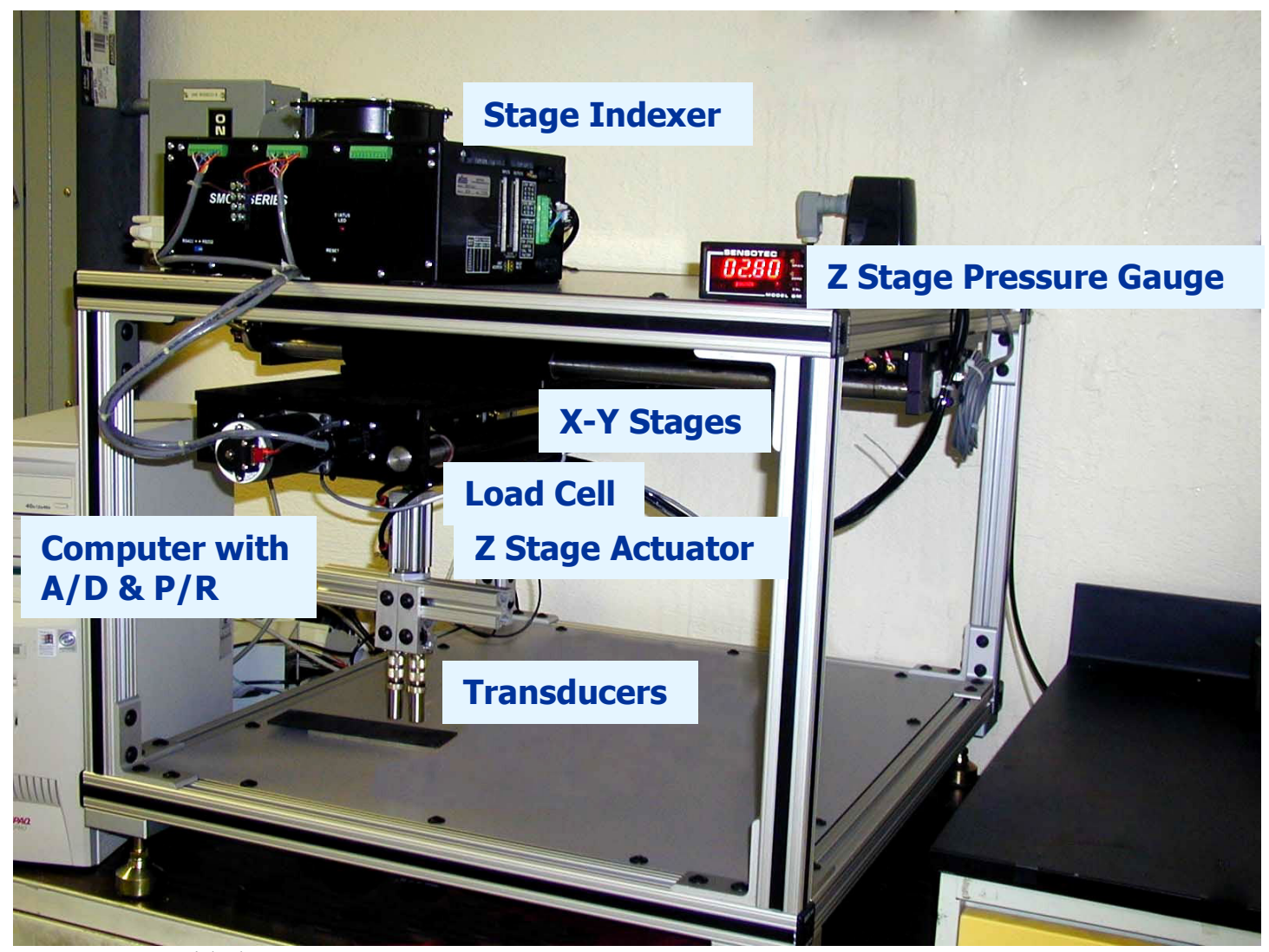

FIGURE 2. Guided Wave Scan System.

- Guided wave scanning can be performed directionally allowing correlations to be made between ultrasonic parameters and directionally-dependent material properties (such as for unidirectional composites or to test the premise of nondirectionality of properties).

- The sample under test does not have to be immersed in fluid (as for most conventional ultrasonic characterization).

Other positive features of guided wave scanning include:

- Guided wave scanning is potentially applicable to components with mildly curved surfaces.

- Guided wave scanning is potentially more versatile in characterizing local modulus changes than is the resonant frequency method [10] since the resonant frequency methods require nodal excitation and generation and are thus not applicable for scanning.

\section{Ultrasonic Signal Analysis}

As mentioned above, the guided wave scan system utilizes the total (multi-mode) ultrasonic response in its inspection analysis. The analysis is based upon the premise of internal absorption and scattering mechanisms being primarily responsible for ultrasonic attenuation with minimal damping due to air, fixturing, and specimen edges. Under these conditions, the morphology of the waveform at the receiving transducer is that of a short duration rise (dominated by early plate wave modes $\mathrm{L}_{11}$ [first symmetric \{longitudinal\} 


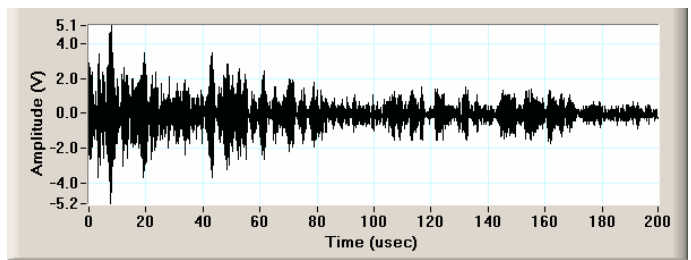

FIGURE 3. Typical morphology of waveform at receiving transducer illustrating exponential decay.

mode] and $\mathrm{L}_{12}$ [first anti-symmetric \{shear\} mode]) followed by an exponentially-decaying portion. A "model" waveform is shown in figure 3.

Analysis is performed in several "domains" in this investigation. First, different parameters associated with the amplitude-based time-domain waveform are calculated. These include centroid mean time and time domain skew factor. The power spectral density (PSD) (frequency domain) of the time-domain signal is calculated and resulting parameters such as Zeroth moment and PSD centroid are obtained. Mathematical expressions for both sets of parameters are provided in [2,5]. Briefly, these parameters are described as follows. Centroid mean time can be thought of as the time in the raw waveform demarcating the location of energy balance. TD skew factor denotes the tilt or shift of the raw waveform towards or away from the beginning of the time interval. The properties of TD Skew Factor are that it varies between +1 and -1 . When it is greater than zero the waveform is skewed toward the beginning of the time interval, as with an exponentially decaying signal. The closer to +1 the time domain skew factor is, the greater the skew towards the beginning of the time interval. Zeroth moment is the area under the PSD and is a measure of energy density. Centroid of the PSD can be thought of as the frequency in the PSD demarcating the location of energy balance. Many other parameters of the time- and frequency-domain waveforms, and their envelopes, are being investigated in terms of their effectiveness for differentiation of material state.

Additionally, the waveform can be described in terms of energy density $\left(|\varphi(f, t)|^{2}\right)$ as a function of time and frequency (amplitude response squared equals energy response) containing frequency dependence since the frequency components of the waveform may change as a function of time. The exponential decaying portion of the waveform can then be expressed by [4]:

$$
|\varphi(f, t)|^{2}=K(f) * \operatorname{Exp}(-\beta(f) t)
$$

where $\beta(f)$ is the frequency-dependent ultrasonic decay rate which describes wave decay over time, and $K(f)$ is the frequency-dependent initial energy density. $\beta(f)$ is analogous to the frequency-dependent attenuation coefficient $\alpha(\mathrm{f})$ which describes wave decay over distance. However, since there is no precise wave path length that is easily defined, the current method for calculation of $\beta(f)$ requires first dividing the time domain wave into time partitions, obtaining power spectral density (PSD) of each partitioned portion of the time domain waveform (using the short-time fourier transform), calculating the area under each PSD curve to obtain energy density (zeroth moment) of each PSD, plotting the energy density values versus the midpoint of each time partition, and obtaining the best exponential fit of this curve from its peak to obtain $K(f)$ and $\beta(f)$. The step of obtaining PSD of each partitioned portion allows one to view how the frequency components of the waveform change over time and is obtained using the short-time fourier transform. 


\section{EXPERIMENTAL}

In this investigation, several ceramic matrix composite specimens were examined using the guided wave scan system. The samples included Silicon Carbide fiber/Silicon Carbide matrix $(\mathrm{SiC} / \mathrm{SiC})$ samples containing delamination and regular pattern of density variation, $\mathrm{SiC} / \mathrm{SiC}$ samples prior to and after silicon infiltration of the carbon (C) perform, and $\mathrm{C} / \mathrm{SiC}$ creep tensile samples undergoing interrupted creep tensile testing. Broadband ultrasonic transducers were employed with center frequencies ranging from 1 to $3.5 \mathrm{MHz}$ (both sender and receiver were of the same frequency). Ultrasound was coupled to the material via elastic coupling pads. Analog-to-digital sampling rates used were $10 \mathrm{MHz}$ to $25 \mathrm{MHz}$. Scan increments varied between 1 and $5 \mathrm{~mm}$. Each sample was scanned 2 to 4 times to characterize reproducibility [8]. As described in the previous section, images constructed included those calculated from centroid mean time, time-domain skew factor, zeroth moment and centroid of the PSD, frequency-dependent ultrasonic decay rate and frequency-dependent energy density initial value. Thermographic NDE utilizing flash lamps and a state-of-the-art high speed camera was used to obtain images of the samples for comparison with the ultrasonic guided wave scan images.

\section{RESULTS}

The $\mathrm{SiC} / \mathrm{SiC}$ sample containing delamination had the delamination most easily discriminated in the centroid mean time and zeroth moment images (whitish areas in figures 4 and 5). Time-domain waveforms associated with the delaminated area and a nondelaminated area are shown in figure $4 \mathrm{~b}$. The shift in centroid mean time away from the origin is quite apparent for the delamination when viewing the waveforms. Power spectral densities associated with the delaminated area and a non-delaminated area are shown in figure $5 \mathrm{~b}$. The increase in the area under the power spectral density (zeroth moment) is quite apparent for the delaminated area. Thermographic images also revealed the delamination.
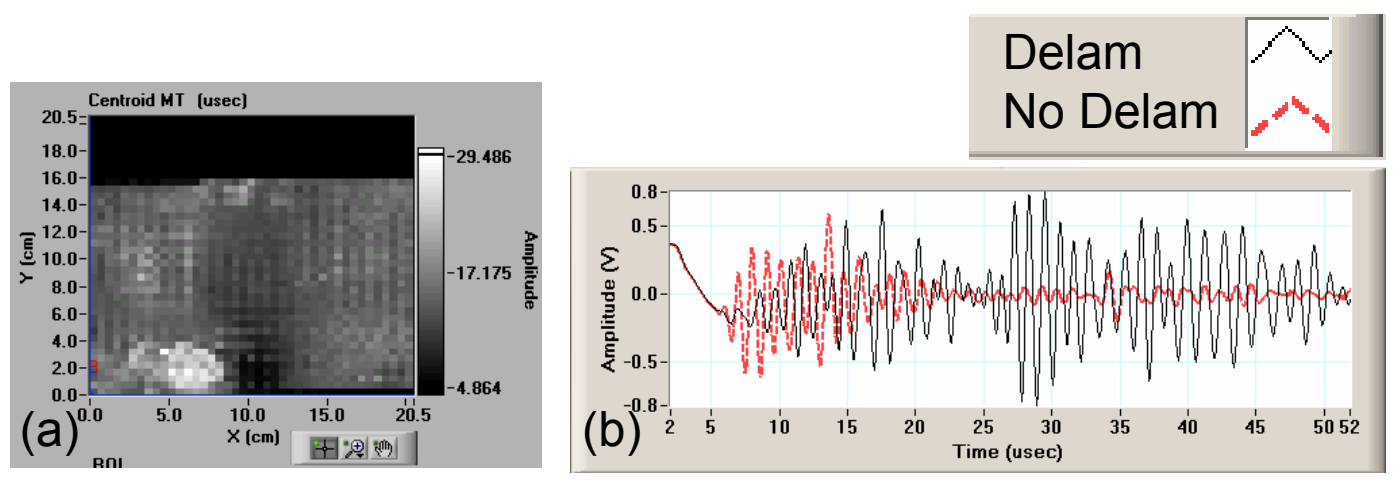

FIGURE 4. a) Centroid mean time image of $\mathrm{SiC} / \mathrm{SiC}$ sample. Whitish area in lower left of image is delaminated area. b) Time-domain waveforms associated with delaminated and non-delaminated area.

The $\mathrm{SiC} / \mathrm{SiC}$ sample containing the regular pattern of density variation had the density variation most easily discriminated in the centroid mean time ("dots" represent lower density areas) (figure 6) and time domain skew factor images (not shown due to space considerations). In this case the change in the morphology of the time domain waveform from a high to a lower density area is much more subtle and one cannot rely on visual discrimination of the waveforms as was possible for the delamination. Instead, one 
must rely solely on the image. Thermographic images also revealed the density variation. Approximately $10 \%$ thickness variation corresponding to the spots of density variation was noted which could affect the ultrasonic results. However, similar ultrasonic results were observed for a plate containing the regular density variation but no appreciable thickness variation [7].
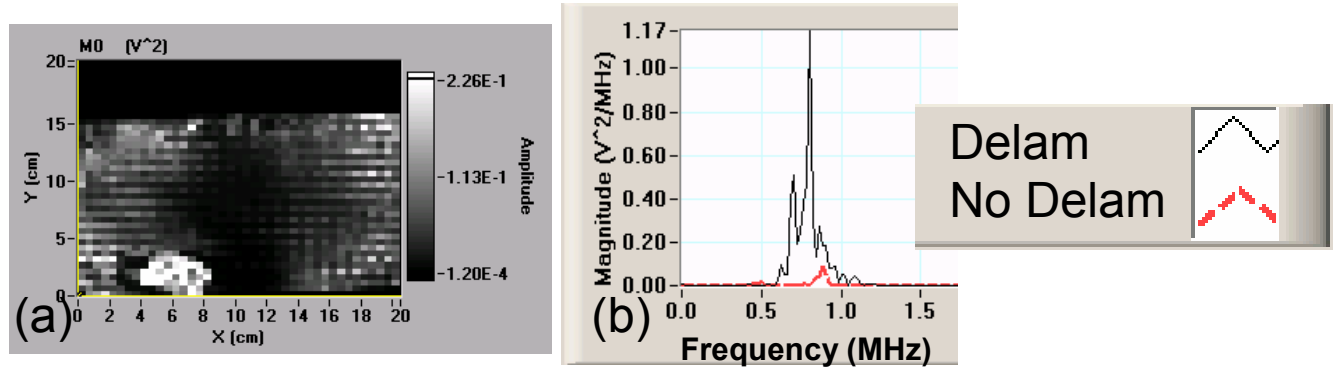

FIGURE 5. a) Zeroth Moment image of $\mathrm{SiC} / \mathrm{SiC}$ sample. Whitish area in lower left of image is delaminated area. b) Power spectral densities associated with delaminated and non-delaminated area.

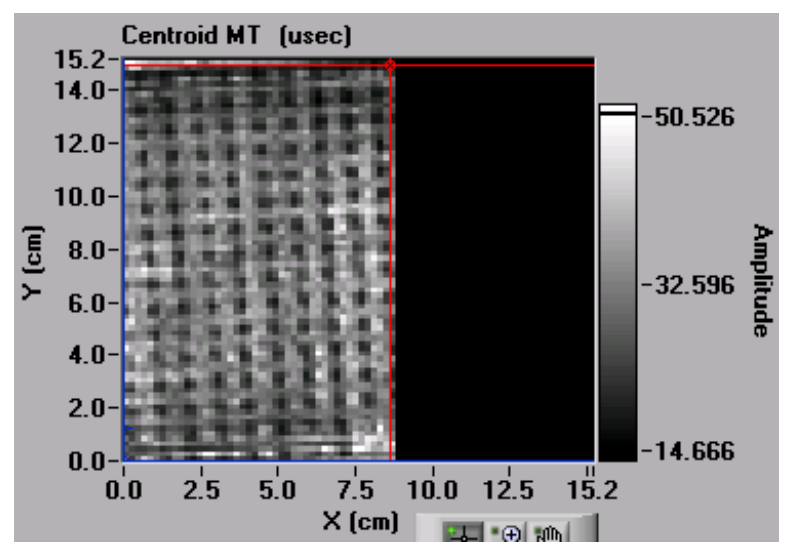

FIGURE 6. Centroid mean time image of $\mathrm{SiC} / \mathrm{SiC}$ sample with regular pattern of density variation.

For the $\mathrm{SiC} / \mathrm{SiC}$ sample prior to and after silicon infiltration of the carbon perform, the zeroth moment increased uniformly over the entire sample 100x after infiltration (from mean $=0.0036 \mathrm{~V}^{2}$ to mean $=0.371 \mathrm{~V}^{2}$ ). Centroid decreased uniformly over $50 \%$ after infiltration (from mean $=0.83 \mathrm{MHz}$ to mean $=0.33 \mathrm{MHz}$ ). Typical power spectral densities clearly discriminate the two microstructural conditions by amplitude, energy density (zeroth moment), and frequency content (centroid) (figure 7). These results can be explained by the fact that the holes in the composite structure are being filled with material (Silicon) making the structure less attenuative. However, it must be noted that the surface condition also changed prior to and after infiltration which likely affected ultrasonic results. 


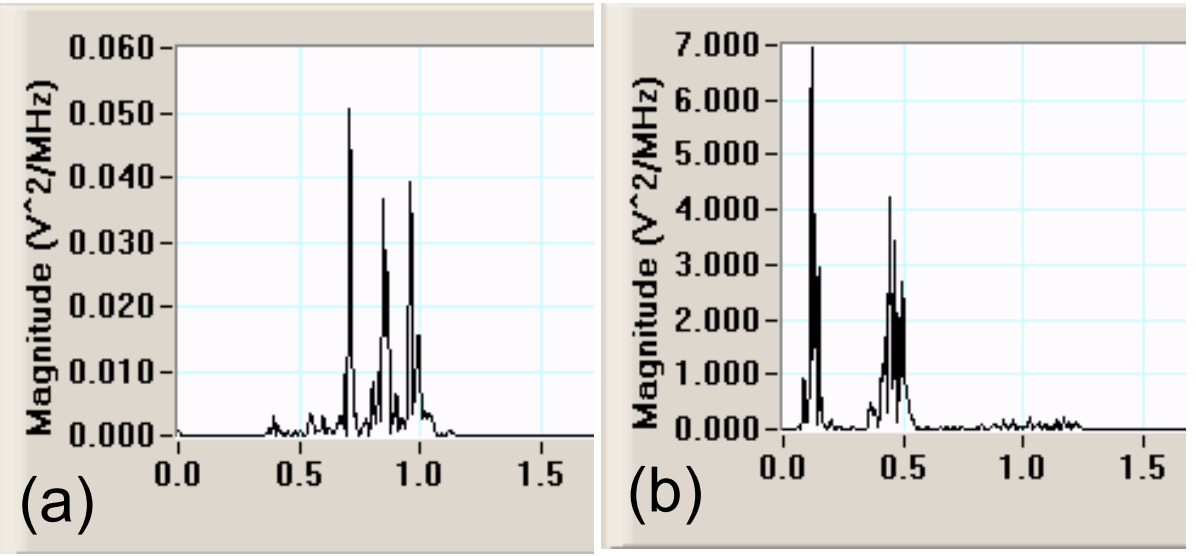

FIGURE 7. Typical power spectral densities a) prior to silicon infiltration of carbon preform and b) after silicon infiltration of carbon preform for $\mathrm{SiC} / \mathrm{SiC}$ sample.

Finally, the $\mathrm{C} / \mathrm{SiC}$ creep-tensile-tested sample scanned had been removed from testing after 16 hours (testing conditions were temperature $=1200{ }^{\circ} \mathrm{C}$, tensile stress $=$ $10 \mathrm{Ksi}$, environment = air). For this sample, the zeroth moment and frequency-dependent ultrasonic decay initial energy clearly showed indications different from the rest of the sample at the $X=10-11 \mathrm{~cm}$ location of the sample (whitish areas) (figure 8). These indications are likely of the crack or open space nature as carbon fibers disappear due to oxidation [1]. The critical points regarding these results include 1) these indications were not apparent by any means after 14 hours of creep-tensile testing which indicated major degradation likely occurred at the $X=10-11 \mathrm{~cm}$ location between 14 and 16 hours of testing, 2) these indications were not apparent in optical or thermographic images after 16 hours but were apparent in the guided wave images noted, and 3) the sample failed at the location of the indication soon after being put back into the creep-tensile testing rig for another 2 hours of testing. The zeroth moment mean decreased an order of magnitude from 14 to 16 hours of creep tensile testing $\left(\sim 0.04 \mathrm{~V}^{2}\right.$ decreased to $\left.\sim 0.004 \mathrm{~V}^{2}\right)$. A similar decrease was seen in ultrasonic decay initial energy mean from 14 to 16 hours $\left(0.724 \mathrm{~V}^{2}\right.$ decreased to $0.083 \mathrm{~V}^{2}$ ).

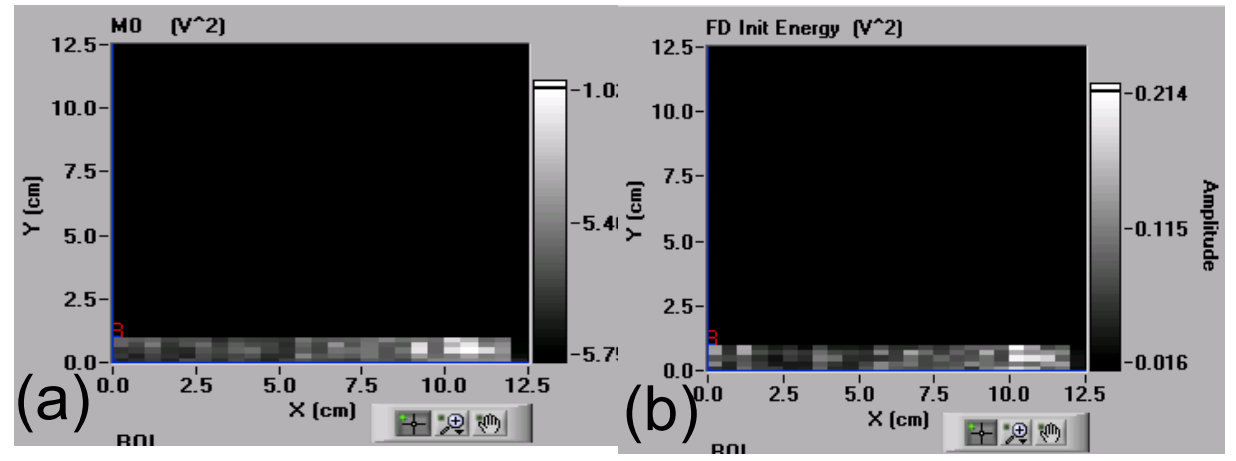

FIGURE 8. a) Zeroth Moment and b) frequency-dependent ultrasonic decay initial energy image for $\mathrm{C} / \mathrm{SiC}$ sample after 16 hours of creep tensile testing. Note white indication in both images at $X=10-11 \mathrm{~cm}$ which was not apparent after 14 hours of testing. 


\section{CONCLUSIONS AND UPDATES}

This article focused on surveying the ability of the multi-mode guided wave scan system for characterizing microstructural changes and defects in $\mathrm{SiC} / \mathrm{SiC}$ and $\mathrm{C} / \mathrm{SiC}$ ceramic matrix composites. Delamination, density variation, microstructural change due to silicon infiltration, and crack space indication, were revealed in images formed from several time- and frequency-domain parameters of the ultrasonic guided wave signal. The crack space indication revealed was not seen by other techniques and was the eventual failure location, both critical results. Zeroth moment and centroid overall seem to be the most consistently sensitive to defect and varying microstructural condition but other parameters such as time domain skew factor and frequency-dependent ultrasonic decay initial energy have provided promising results. Many other time- and frequency-domain parameters are being investigated. Which parameters prove most promising might be material and microstructural-condition dependent. Therefore, it may be critical to form and view many parameter images together as the scan proceeds which is a capability the guided wave scan system has. Theoretical modeling is needed to explain results seen and actual standards need to be developed to aid in the theoretical modeling.

A description of the initial version of the NASA GRC guided wave scan system was given in [7-9]. Since that period, several updates have occurred. First, a pci-based $25 \mathrm{MHz}$ pulser-receiver card was added to the computer so that external pulser-receiver and preamplifier were no longer needed. The only instrument that currently resides outside of the computer (aside from the scanning hardware) is the motion controller/indexer. Second, the scan system has been assembled into a frame with the motion controller mounted on the frame for more compact and robust construction (figure 2). Third, a second receiving transducer has been added to allow guided wave velocities to be mapped (the results for which are to be described in a future article) (not shown). (The sending and receiving transducers can also be manually adjusted for distance between them with future plans to automate this capability.) Fourth, the software has been modified for the latter and also for greater flexibility in user choice of signal processing parameters and images to be calculated (ability to choose up to 18 out of a possible 30 time- and frequency-domain parameters to form images from as the scan proceeds). Fifth, the option now exists to analyze specific time portions of the time-domain waveform as well as tuning/filtering for specific frequency ranges of interest in the frequency domain. Sixth, the on-line ability to compare waveforms, power spectral densities, and ultrasonic decay curves at different locations of samples is possible. Seventh, precise control of load via automated air pressure valve adjustment has been added. These additions are pertinent to the eventual commercialization/technology transfer of the scan system and allow for a great number of future research and materials characterization opportunities. Future modifications will be implemented as needed (such as to accommodate mildly curved components and for tuning for specific modes of ultrasound, and for non-contact operation). 


\section{REFERENCES}

1. Verrilli, M.J., Kantzos, P.T., and Telesman, J., "Characterization of Damage Accumulation in a $\mathrm{C} / \mathrm{SiC}$ Composite Subjected to Mechanical Loadings at Elevated Temperature," in the proceedings of Environmental, Mechanical, and Thermal Properties and Performance of Continuous Fiber Ceramic Composite (CFCC) Materials and Components, ASTM STP 1392, M. G. Jenkins, Ed., American Society for Testing and Materials, West Conshohocken, PA, 2000.

2. Cawley, P., Lowe, M.J.S., Alleyne, D.N., Pavlakovic, B. and Wilcox, P. "Practical Long Range Guided Wave Testing: Application to Pipes and Rails," Materials Evaluation, Vol. 61, No. 1, pp. 66-74 (2003).

3. Rose, J.L., "Standing on the Shoulders of Giants-An Example of Guided Wave Inspection," Materials Evaluation, Vol. 60, No. 1, pp. 53-59 (2002).

4. Kautz, H.E., "Acousto-Ultrasonics to Assess Material and Structural Properties," NASA/CR-2002-211881 (2002).

5. Rose, J.L. and Soley, L.E., "Ultrasonic Guided Waves for Anomaly Detection in Aircraft Components," Materials Evaluation, Vol. 58, No. 9, pp. 1080-1086 (2000).

6. Gyekenyesi, A.L., Kautz H.E., and Cao, W., "Damage Assessment of Creep Tested and Thermally Aged Udimet 520 Using Acousto-Ultrasonics," NASA/TM-2001-210988, (2001).

7. Roth, D.J., Martin, R.E, Harmon, L.M., Gyekenyesi, A.L. and Kautz, H.E., Development of a High Performance Acousto-Ultrasonic Scan System, NASA/TM2002-211913, (2002).

8. Martin R.E., Gyekenyesi A.L., and Roth D.J., "The Development and Testing of an Automated Acousto-Ultrasonic Scan System" Presented at SPIE's Conference on Nondestructive Evaluation and Health Monitoring of Aerospace Materials and Composites, March 2003, San Diego, CA.

9. Roth, D.J., Verrilli, M.J., Martin, R.E, Harmon, L.M., and Gyekenyesi, A.L., "Characterization of C/Enhanced SiC Composite Creep Damage Using An Ultrasonic Guided Wave Scan System," Presentation and Proceedings of 27th Annual Conference on Composites, Materials, and Structures, January 27-30, 2003, Radisson Resort at the Port, Cape Canaveral/Cocoa Beach, FL.

10. ASTM Standard: C1259-96 "Standard Test Method for Dynamic Young's Modulus, Shear Modulus, and Poisson's Ratio for Advanced Ceramics by Impulse Excitation of Vibration." 
Public reporting burden for this collection of information is estimated to average 1 hour per response, including the time for reviewing instructions, searching existing data sources, gathering and maintaining the data needed, and completing and reviewing the collection of information. Send comments regarding this burden estimate or any other aspect of this collection of information, including suggestions for reducing this burden, to Washington Headquarters Services, Directorate for Information Operations and Reports, 1215 Jefferson Davis Highway, Suite 1204, Arlington, VA 22202-4302, and to the Office of Management and Budget, Paperwork Reduction Project (0704-0188), Washington, DC 20503.

\begin{tabular}{|l|l|l}
\hline 1. AGENCY USE ONLY (Leave blank) & $\begin{array}{r}\text { 2. REPORT DATE } \\
\text { September } 2003\end{array}$ & $\begin{array}{r}\text { 3. REPORT TYPE AND DATES COVERED } \\
\text { Technical Memorandum }\end{array}$ \\
\hline
\end{tabular}

4. TITLE AND SUBTITLE

5. FUNDING NUMBERS

Microstructural and Defect Characterization in Ceramic Composites Using an Ultrasonic Guided Wave Scan System

6. AUTHOR(S)

WBS-22-714-04-17

D.J. Roth, L.M. Cosgriff, R.E. Martin, M.J. Verrilli, and R.T. Bhatt

7. PERFORMING ORGANIZATION NAME(S) AND ADDRESS(ES)

8. PERFORMING ORGANIZATION REPORT NUMBER

National Aeronautics and Space Administration

John H. Glenn Research Center at Lewis Field

Cleveland, Ohio 44135-3191

E-14080

9. SPONSORING/MONITORING AGENCY NAME(S) AND ADDRESS(ES)

10. SPONSORING/MONITORING AGENCY REPORT NUMBER

National Aeronautics and Space Administration

Washington, DC 20546-0001

NASA TM-2003-212518

\section{SUPPLEMENTARY NOTES}

Prepared for the 30th Annual Review of Quantitative Nondestructive Evaluation (QNDE) sponsored by the Quantitative Nondestructive Evaluation (QNDE) Programs, Green Bay, Wisconsin, July 27-August 1, 2003. D.J. Roth, NASA Glenn Research Center; L.M. Cosgriff and R.E. Martin, Cleveland State University, Cleveland, Ohio and NASA Resident Research Associate at Glenn Research Center; M.J. Verrilli, NASA Glenn Research Center; and R.T. Bhatt, U.S. Army Research Laboratory at NASA Glenn Research Center. Responsible person, D.J. Roth, organization code 5920, 216-433-6017.

\begin{tabular}{|l|l}
\hline 12a. DISTRIBUTION/AVAILABILITY STATEMENT & 12b. DISTRIBUTION CODE
\end{tabular}

Unclassified - Unlimited

Subject Categories: 24 and 38

Distribution: Nonstandard

Available electronically at http://gltrs.grc.nasa.gov

This publication is available from the NASA Center for AeroSpace Information, 301-621-0390.

13. ABSTRACT (Maximum 200 words)

In this study, an ultrasonic guided wave scan system was used to characterize various microstructural and flaw conditions in two types of ceramic matrix composites, $\mathrm{SiC} / \mathrm{SiC}$ and $\mathrm{C} / \mathrm{SiC}$. Rather than attempting to isolate specific lamb wave modes to use for characterization (as is desired for many types of guided wave inspection problems), the guided wave scan system utilizes the total (multi-mode) ultrasonic response in its inspection analysis. Several timeand frequency-domain parameters are calculated from the ultrasonic guided wave signal at each scan location to form images. Microstructural and defect conditions examined include delamination, density variation, cracking, and pre/ post-infiltration. Results are compared with thermographic imaging methods. Although the guided wave technique is commonly used so scanning can be eliminated, applying the technique in the scanning mode allows a more precise characterization of defect conditions.

\section{SUBJECT TERMS}

Guided waves; Composites; Ceramics; Scanning; Composites

17. SECURITY CLASSIFICATION OF REPORT

Unclassified
18. SECURITY CLASSIFICATION OF THIS PAGE

Unclassified
19. SECURITY CLASSIFICATION OF ABSTRACT

Unclassified
15. NUMBER OF PAGES

15

16. PRICE CODE

20. LIMITATION OF ABSTRACT

Standard Form 298 (Rev. 2-89)

Prescribed by ANSI Std. Z39-18 298-102 